\title{
Implications of the Global Financial Crisis for China: A Dynamic CGE Analysis to 2020
}

\author{
Anna Strutt ${ }^{1,2}$ and Terrie Walmsley ${ }^{3,4}$ \\ ${ }^{1}$ Department of Economics, Waikato Management School, Hamilton 3240, New Zealand \\ ${ }^{2}$ School of Economics, University of Adelaide, Adelaide, SA 5005, Australia \\ ${ }^{3}$ Center for Global Trade Analysis, Purdue University, West Lafayette, IN 47906, USA \\ ${ }^{4}$ Department of Economics, University of Melbourne, Parkville, VIC 3010, Australia \\ Correspondence should be addressed to Anna Strutt, astrutt@waikato.ac.nz
}

Received 2 June 2011; Accepted 4 August 2011

Academic Editor: James R. Barth

Copyright ( $\odot 2011$ A. Strutt and T. Walmsley. This is an open access article distributed under the Creative Commons Attribution License, which permits unrestricted use, distribution, and reproduction in any medium, provided the original work is properly cited.

\begin{abstract}
The global financial crisis resulted in a significant downturn in the global economy, with impacts felt throughout the world. In this paper, we use a dynamic global general equilibrium model to explore the longer-term impacts of the financial crisis, with a particular focus on China. The economies of most countries suffered to some extent, with the extent of declines in the long run likely to depend on the extent to which investment declines. Our results suggest that overall the financial crisis leads to international trade falling by approximately 14 percent from the 2020 baseline level. Within this, the composition of trade changes, particularly reflecting changes in demand for construction of investment goods and increasing longer-term demand from economies like China. We also briefly consider the impact of a more protracted recovery from the crisis, which has even more significant impacts on the global economy.
\end{abstract}

\section{Introduction}

The global financial crisis resulted in a significant downturn in the global economy. Although the worst of the crisis appears over at the time of writing, the global recovery "remains exposed to significant risks" (2011). This paper uses a dynamic computable general equilibrium (CGE) model to explore some potential effects of the global financial crisis for China.

To examine the impacts of the crisis, we use GDyn, a dynamic global CGE model, developed by Ianchovichina and McDougall [2] and based on the GTAP model [3]. The GDyn model incorporates most features of the GTAP model, including bilateral trade flows, a sophisticated consumer demand function and intersectoral factor mobility. In addition, GDyn tracks foreign ownership of capital and investment behavior. This allows us to include the impacts of endogenous capital accumulation and the movement of investment between countries in response to differing expected rates of return. Use of a dynamic model also allows us to model consecutive periods of the crisis and the consequent time-path of adjustment for each economy. While
GDyn has an improved treatment of investment relative to the GTAP model and captures errors in expectations, it does not model debt obligations or money and, therefore, does not purport to explain the financial crisis. Thus, we use the model to mimic key macroeconomic impacts of the financial crisis, in an effort to shed light on the longer-term impacts of the crisis for China.

We first explain the model and develop a baseline scenario for GDyn, which depicts how the global economy might have evolved without the impact of the global financial crisis. This is then compared with results arising with the global financial crisis. We also consider the potential impacts of a slower recovery from the crisis. Finally, we offer some concluding comments, including discussing some limitations of the current study.

\section{Model and Baseline Scenario}

The GDyn model incorporates a treatment of investment that relies on (a) the gradual elimination of errors in expectations, (b) the gradual equalization of rates of return to investment, and (c) the gradual movement of economies towards 
steady-state growth [2]. We adapt the model for our current purposes to include endogenously determined employment of skilled and unskilled labour, along with capital.

In combination with the GDyn model, we use version 7 of the GTAP Data Base, which has a base year of 2004 [4]. This database is augmented with supplementary data required for the GDyn model [5]. The 113 countries/regions and 57 sectors in the full GTAP Data Base are aggregated to 29 regions and 27 sectors. However, we focus here on results for China, contrasting them with a limited selection of other countries.

2.1. Developing the Baseline Scenario. Before examining the impacts of the global financial crisis, we first develop a baseline for the model which represents how the global economy might have looked in the absence of the crisis. The development of a baseline is an important component of the experimental design when using a dynamic model [6]; however, building a suitable baseline is a complex task.

Given the difficulties in creating a baseline for the GDyn model, previous baselines have focused on obtaining projections for a few key macroeconomic variables, such as real GDP, population, skilled and unskilled labour, along with implementation of key policies which have already been agreed upon and are expected to affect the regions/sectors being considered [7]. An alternative approach, developed by Dixon and Rimmer [8] for single country model baselines, uses a series of simulations (historical, decomposition, and forecasting) to develop a baseline scenario. We use a combination of these approaches, focusing on the path of the macrovariables. Previous work with GDyn indicated that the way we model errors in expectation and productivity changes tends to have significant impacts on the baseline [9]; therefore, we focus particularly on improving the specification of these. Key aspects of our baseline are summarised below.

2.1.1. Data Sources. Historical data were collected primarily from the World Development Indicators for available countries [10]. Some additional data for the Asian economies were also collected. (We are grateful to Ginalyn Komoto and Susan Stone, previously of ADBI, for their assistance in collating this additional data.) Historical data were generally found to be particularly good prior to 2006. We use the available historical data to find average annual growth rates and construct an historical baseline. We then include the following variables in the baseline: real GDP, investment, consumption, government spending, population, and skilled and unskilled labour.

2.1.2. Structural Change and Sectoral Productivity. A range of alternative assumptions are possible with respect to sectoral productivity differentials over time. Ngai and Pissarides [11] discuss two competing explanations for structural change: the technological explanation attributes it to differences in sectoral rates of total factor productivity, while the utilitybased explanation relies on different income elasticities for different goods leading to structural change. However, these two explanations may coexist [11], and, in the current work, both contribute to structural change over time in the economies we model. We retain the standard GTAP approach to modelling utility and income elasticities $[3,4]$, therefore, we concentrate here on explaining the approach taken to modelling sectoral productivity growth.

The assumptions we make on sectoral productivity growth broadly follow the approach of Hertel et al. [12] and Golub et al. [13], which based nonagricultural productivity growth on economy-wide labour productivity growth rates, adjusted for productivity differences across sectors. We update the labour productivity differentials using the latest available OECD estimates, (which provide estimates from 1995-2003, contrasting with previous estimates based on 1970-90 data) employ greater sectoral differentiation and also apply this approach to agricultural sectors. Sectoral differentials for labour productivity growth rates are derived from the OECD STAN data [14]. These data provide estimates of labour productivity in terms of the amount of value added per unit of input. Following the approach of Kets and Lejour [15], these indexes of sectoral labour productivity growth are averaged across countries. (We use a simple average as recommended by Kets and Lejour for this kind of labour productivity data.) To estimate sectoral differentials, the average growth in labour productivity growth for each sector is assessed relative to average labour productivity growth. Other studies have employed different assumptions for land-using sectors, taking into account the productivity of all inputs, rather than just the value added [12, 13, 16].

Table 1 summarises our estimated sectoral productivity differentials, following the approach outlined above. Consistent with previous studies, a relatively high level of productivity growth is indicated for agricultural sectors. In addition, certain other sectors also experience relatively high productivity growth, particularly some of the manufacturing sectors such as electronics, machinery, and motor vehicles. These findings are broadly consistent with the earlier work of Kets and Lejour [15], including the finding of particularly high growth rates in the transport and communication sector. Since we define these sectoral differentials as the ratio of labour productivity growth in each sector to the economywide average, they are implemented for each region by multiplying by the base factor productivity growth rate for each region. Thus, although we only present sectoral differentials in Table 1, the effective impact of these differentials will vary significantly by regions, with the relatively rapidly growing economy of China having a high base factor productivity growth rate.

2.1.3. Calibration of the Baseline. As outlined in Walmsley [7], historical investment can be accommodated in one of two ways: (a) by introducing an additional risk premium to explain the difference between actual and model determined investment or (b) by introducing errors in expectations. The difference between the two alternatives stems from assumptions regarding their permanence into the long run. In the first case, large risk premiums may be created by low investment in some countries, and these risk premiums are permanent, and; therefore, low investment remains in the long run. This method would be appropriate for a country 
TABLE 1: Estimated sectoral productivity differentials.

\begin{tabular}{llll}
\hline Sectors & Productivity differentials & Sectors & Productivity differentials \\
\hline Agriculture and forestry & 1.75 & Chemicals, rubber, and plastics & 1.62 \\
Processed foods & 0.60 & Metals & 1.54 \\
Extraction & 1.42 & Metal Products & 1.17 \\
Textiles, apparel, and leather products & 1.39 & Other manufactured products & 1.17 \\
Wood and paper products & 1.63 & Utilities & 1.76 \\
Motor vehicles & 2.12 & Construction & 0.27 \\
Electronics & 3.71 & Transport and communication & 2.14 \\
Other machinery & 2.55 & Business services & 0.47 \\
Petroleum and coal products & 1.61 & Housing, education, and health & 0.33 \\
\hline
\end{tabular}

Source: authors' estimates based on OECD data [14].

like China where recent increases in investment are thought to be the result of a more open policy towards foreign trade and investment in general, resulting in a permanent fall in the risk premiums and a permanent rise in investment. In the second case, large differences in historical and modeldetermined investment are assumed to be the result of large errors in expectations by investors. Eventually, investors will realize they have been making errors, and; hence, these errors will be eliminated, and investment will adjust in the long run. This method is more appropriate for a country where investment cannot be completely explained by rate of return differentials or differences in risk premiums. For instance, many commentators and economists did express concerns about the, seemingly unexplainable, continuous inflow of foreign investment into the USA and ballooning trade deficits for many years prior to the crisis. Since the difference between the two methods is simply how permanent the change is, we chose not to make ad hoc judgments of each country but instead use the term "errors in expectations" and then allow the actual data and forecasts to calibrate how the errors change over time with and without the financial crisis. The reader may choose to substitute "risk premia" wherever they see "errors" if they wish.

We simulate a business-as-usual scenario from 2004 to 2007 to calibrate the changes in errors in expectations required to explain the actual investment over this period, and we use real GDP data to calibrate technological change in the baseline. (This calibration baseline is based on and utilizes some of the findings from the work undertaken by Walmsley and Strutt [9] using the GTAP 6 Data Base.) We find that the errors in expectations are generally consistent and positive over the period. Relatively high errors in expectations tend to be found in the developed (and some developing) economies, suggesting that investment tends to be higher than what theory would predict given the current rates of return. The resulting errors in expectation for the US, Japan, and the EU are also consistent with the hypothesis that actual investment has been higher than what current rates of return would predict, due to large errors in expectations (or low-risk premiums). We include these calibrated errors in expectations in the baseline and assume that these errors in expectations continue to be held in the baseline over the whole simulated period 2004-2020. We also extend the
TABLE 2: Average annual changes in selected exogenous and endogenous variables in the baseline, China and selected countries.

\begin{tabular}{lcccc}
\hline & China & Japan & US & EU27 \\
\hline Real GDP & 11.05 & 1.97 & 2.91 & 2.44 \\
Technological change & 5.38 & 2.00 & 1.32 & 1.67 \\
Population & 0.25 & 2.42 & 4.63 & 1.83 \\
Real investment & 16.25 & 0.45 & 4.43 & 1.55 \\
Errors in expectations/risk premia & 16.26 & 17.12 & 20.33 & 18.35 \\
Real supply of unskilled labour & 1.23 & -0.16 & 1.21 & 0.17 \\
Real supply of skilled labour & 3.69 & -0.66 & 1.22 & 0.31 \\
\hline
\end{tabular}

average annual shocks obtained from the calibration of key macrovariables out to 2020. The results from the calibration are shown for selected countries in Table 2.

\section{Scenarios Modeled}

While the GDyn model has improved our ability to track foreign capital flows, as discussed earlier, the model does not profess to be useful in predicting the extent of the financial crisis. Our aim is, therefore, to mimic the behavior of the crisis to assess the likely impact on production and trade. We also consider the impact of a more protracted recovery period.

3.1. Financial Crisis Scenario. The financial crisis Scenario models the impact of the financial crisis through four mechanisms with investment recovering to precrisis levels in 2012. First, we argue that the financial crisis was caused by investors readjusting their expectations of the US and EU returns on investment relative to other countries, in light of news about fundamental problems with the US banking system that also affected the viability of the EU banking system. This is implemented by calibrating the changes in errors in expectations required to track changes in (forecasted) investment in each region between 2007 and 2011, as estimated by the World Bank [17]. We find that expectations of rates of return have been adjusted downwards across the world as investors reevaluate their expectations about the profitability of their investments as a result of the financial crisis. The global 


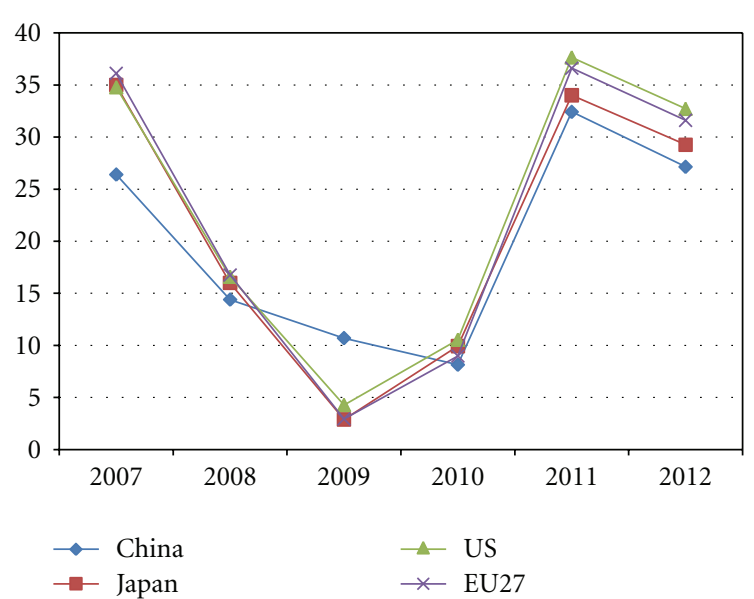

Figure 1: Path of errors in expectations for China and selected countries with financial crisis.

decline in expectations, however, hides the fact that the readjustment has not affected all economies equally. Figure 1 indicates that China moved from being in the bottom position in 2007 to the highest in 2009, in terms of expectations, while the relative positions of the US and Europe have moved in the opposite direction. This pattern reflects the fact that investment in China has been less affected by the crisis than the US and Europe. In 2010 and 2011, expectations rise again, with the US and Europe returning to their relative precrisis positions with higher expectations than China. Therefore, in this scenario, we assume that after 2011 the crisis is essentially over, and the relative attractiveness of investment returns to precrisis levels. (Note that while this assumption was in line with the World Bank forecasts, it could also be argued that changes in relative errors in expectations may continue. That is US errors (and investment growth) might be permanently lower than the baseline. This reflects the fact that economists have for some time argued that the rate of growth of the US trade deficit is unsustainable and that adjustments would eventually be required to bring it back into a long-run sustainable equilibrium. Under this assumption, there is a readjustment of investment across regions, and as a result some countries (e.g., China) experience increased investment which leads to increased capital accumulation and growth in the long run, at the expense of the US economy. Strutt and Walmsley [18] explored this possibility, and it appears an area worthy of future study.)

Second, in addition to the changes in expectations about future returns to capital/investment, we argue that the crisis causes an immediate but temporary decrease in efficiency and return to capital in all countries. Between 2007 and 2011, this decrease in efficiency is obtained through calibration to the decrease required for real GDP to decline by expected impacts of the crisis [17]. With the exception of the US, the baseline changes in technology in 2007 were similar to previous years, and these, along with the changes in investment, and employment explained most of the change in real GDP in that year. Hence no decline in capital efficiency was experienced outside the US in 2007. After 2007, the contagion affects of the crisis could be felt on
TABLE 3: Calibrated changes in technological change and capital efficiency due to the crisis, China and selected regions.

\begin{tabular}{lccccc}
\hline & 2007 & 2008 & 2009 & 2010 & 2011 \\
\hline China & 0.00 & -3.16 & -8.44 & -5.64 & -2.92 \\
Japan & 0.00 & -1.11 & -3.13 & -4.97 & -3.07 \\
US & -0.54 & -1.55 & -4.10 & -5.36 & -4.75 \\
EU27 & 0.00 & -1.22 & -3.05 & -3.38 & -3.21 \\
\hline
\end{tabular}

capital efficiency across the world, with impacts for China and selected countries indicated in Table 3. After 2011 the decrease in efficiency of capital is assumed to end, returning to baseline levels by 2012 .

Third, unemployment of skilled and unskilled labour and capital are modeled through a complementarity [19], which sets employment equal to the natural rate of employment, unless real wages must fall by more than a threshold rate to achieve this. (The threshold rate is greater than zero because there is some evidence that real wages have declined in response to the crisis. The threshold rate depends on the extent to which unemployment is higher than the natural rate of unemployment, where the relation is non-linear. It is assumed that as unemployment rises, the extent to which workers will accept declines in their wages increases. Note that this threshold rate can be altered, depending on the extent to which we believe real wages are flexible.) If real wages are required to fall by more than this, we fix the change in real wages at this threshold rate and allow employment to adjust endogenously. In the next period, the employment rate will attempt to move back to the natural rate again, but this will only be achieved if to do so requires less than the threshold percentage change in the real wage. If a larger decline is required, the change in the real wage will be fixed, and the employment rate will again be determined endogenously. Provided the economy does not continue to be hit by negative shocks, employment is expected to gradually move back to full employment.

Fourth, we include implementation of some of the known fiscal stimulus. (For further detailed country information on stimulus packages for WTO member countries, see the WTO reports $[10,17]$.) The global financial crisis led to substantial and rapid responses, with many governments implementing stimulus packages in an effort to dampen the impact on their domestic economies [17, 20, 21]. However, it is difficult to precisely quantify the fiscal stimulus packages being implemented, with the absence of a standard definition of implementation making cross-country comparisons very difficult [22]. In Table 4, we provide a summary of the government spending growth. The growth in government spending increased significantly in 2009 for some countries, including the US, EU, and particularly Japan, with some tapering-off suggested for 2010 and 2011. We note the tendency to focus on fiscal stimulus, in contrast to the Great Depression of the 1930s [23]. The implications of this are important since monetary stimulus benefited the initiating country but had a negative impact on its trading partners, while the use of different fiscal stimulus policy instruments today tends to benefit trading partners as well as 
TABLE 4: Fiscal stimulus: assumed government consumption growth rates (\%).

\begin{tabular}{lccccc}
\hline & 2007 & 2008 & 2009 & 2010 & 2011 \\
\hline Australia & 2.4 & 3.6 & 4.0 & 3.5 & 3.0 \\
China & 11.2 & 10.7 & 10.0 & 10.2 & 9.0 \\
Hong Kong & 3.0 & 1.7 & 5.0 & 4.0 & 3.0 \\
Taiwan & 0.9 & 1.1 & 12.0 & 8.0 & 7.0 \\
Japan & 1.9 & 0.8 & 6.5 & 4.0 & 4.0 \\
Korea & 5.4 & 4.2 & 6.0 & 5.0 & 4.0 \\
India & 7.0 & 20.3 & 10.0 & 5.0 & 4.0 \\
US & 2.1 & 2.9 & 4.0 & 4.0 & 3.0 \\
EU & 2.2 & 1.6 & 3.7 & 3.1 & 2.3 \\
Russia & 3.4 & 2.4 & 1.0 & 1.0 & 3.0 \\
\hline
\end{tabular}

a Euro zone.

Source: World Bank [17].

the country implementing the stimulus [23]. (Albeit many of the stimulus packages currently being implemented do include "buy local" clauses.)

We assume that the fiscal stimulus diverts savings from investment towards funding of fiscal deficits. (Ordinarily the GDyn model would divert income from both savings and private consumption towards government spending. We have allowed the diversion to be greater on savings for two reasons: first, government must pay for these deficits through increasing debt and so reduce savings available for private investment, and, secondly, it allows us to capture the global decline in savings available for investment.) The fiscal stimulus and decline in savings are incorporated over the period 2007 to 2011. After 2011, no further changes are made, so that the share of government spending and savings are assumed to remain fixed.

3.2. Extended Financial Crisis Scenario. In the previous, case we used the World Bank forecasts to calibrate forecast changes in investment and real GDP. The calibrated changes in errors in expectations show that there is an expectation that after 2012 errors in expectations and investment would go back to precrisis levels. The second scenario of an extended financial crisis models the impact of a more protracted financial crisis, with investment recovering only gradually after 2010 and not returning to precrisis levels until 2015. As in the first scenario, the changes in errors in expectations in the US, Europe, and the rest of the world are found by calibration between 2007 and 2010. After 2010, errors slowly adjust so that investment growth rates return to baseline levels by 2015 (not 2012, as in the first scenario). Moreover the temporary decrease in efficiency continues to 2015, albeit the decline is gradually eliminated so that by 2015 the technological change has returned to baseline levels.

\section{Results and Discussion}

We focus particularly on the first financial crisis scenario, before briefly exploring potential implications of an extended financial crisis.

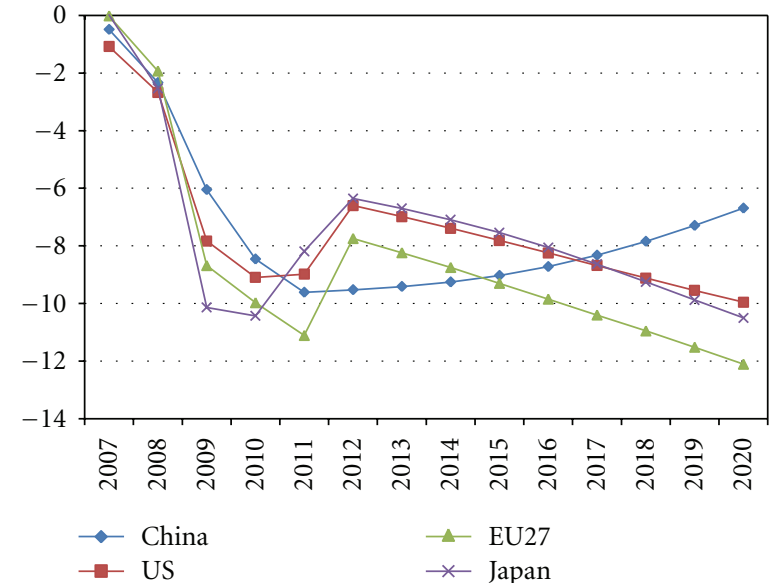

Figure 2: Cumulative differences in real GDP, selected countries, relative to baseline (\%).

Table 5 presents the macroeconomic findings for China and selected countries under the financial crisis scenario, with all results being cumulative percentage differences from the baseline in 2020. (To interpret the results, take the example of Chinese real GDP of -6.7 percent: this means that in 2020 China's real GDP would be 6.7 percent lower than it would have been, had the crisis not occurred.) There are sometimes considerable differences between the short run (2010) and long run (2020), with real GDP results shown for both 2010 and 2020.

Given our assumptions for the Financial Crisis scenario, a key impact will be lower real GDP, with the most significant losses occurring between 2007 and 2011 (Figure 2). During this period, all economies experience a downturn relative to the baseline as capital efficiency, trade, and employment fall. The subsequent rate of recovery is related to the gains in investment, with investment moving towards those countries with the highest relative rates of return. China is able to partially recover the reductions experienced in 2010 GDP, with the cumulative impact on real GDP approximately 2 percent smaller in 2020 than in 2010. However, as Figure 2 shows, for the US, Japan, and particularly the EU27, the reduction in GDP due to the financial crisis is even greater in 2020 than in 2010. This reflects ongoing reallocation of investment away from these regions in our modeling results.

Figure 3 illustrates the cumulative growth in real GDP for China and the US in the baseline and as a result of the crisis, with the difference between the two curves representing the impact of the crisis. There is a fairly pronounced impact on the US economy, given that growth rates even without the crisis were likely to be relatively modest. However, for China, growth rates are only marginally affected, particularly when considered relative to the strong gains projected over this period to 2020.

The changes in investment summarized for China and selected countries in Table 5 indicate some significant differences, reflecting the fact that the financial crisis has resulted in a readjustment of investment globally. This relocation of investment is also reflected in the adjustments of the 
TABLE 5: Cumulative difference in selected macroeconomic variables, financial crisis relative to 2020 baseline in China and selected countries $(\%)$.

\begin{tabular}{lcccccc}
\hline & Real GDP in 2010 & Real GDP in 2020 & Investment & Real exports & Real imports & Change in trade balance (US\$b) \\
\hline China & -8.5 & -6.7 & 27.6 & -20.1 & -10.1 & -222.5 \\
Japan & -10.4 & -10.5 & -32.5 & -20.6 & -13.7 & 15.6 \\
US & -9.1 & -9.9 & -38.4 & -8.5 & -18.3 & 388.8 \\
EU27 & -10.0 & -12.1 & -29.7 & -16.2 & -15.8 & 286.9 \\
\hline
\end{tabular}

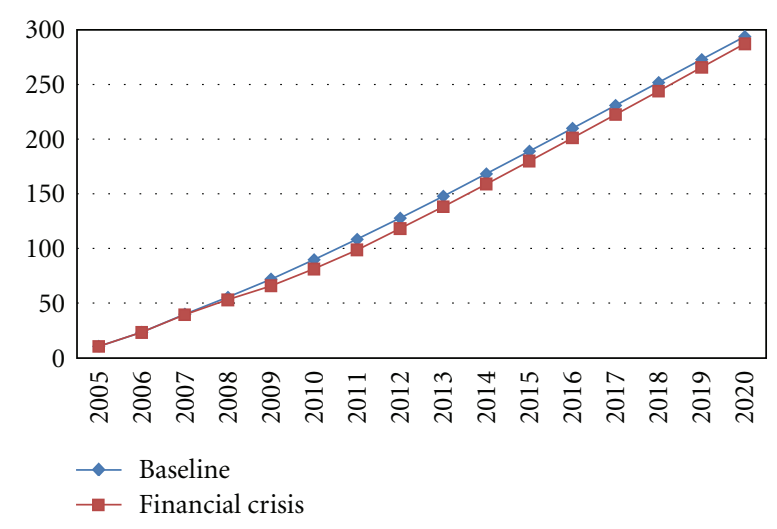

(a) China

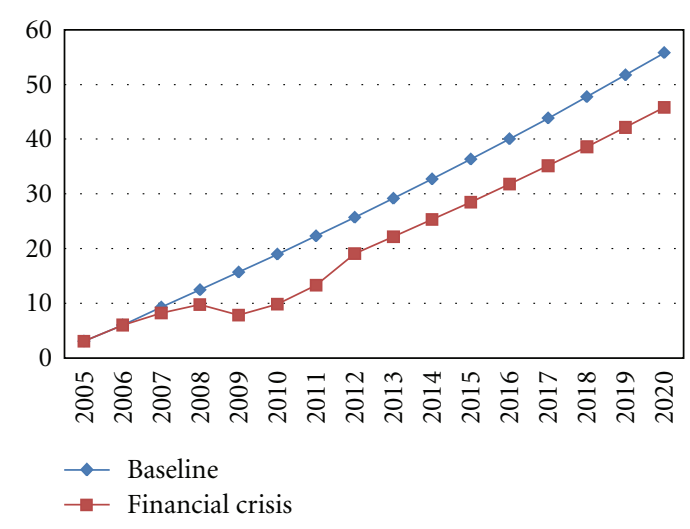

(b) United States

FIGURE 3: Cumulative changes in the baseline's and financial crisis's real GDP (\%).

trade balances. For example, China experiences a 28 percent increase in investment and a decrease in its trade surplus, relative to the 2020 baseline. (We do not specifically constrain trade imbalances over time, and, in the baseline, China's trade surplus continues to increase. However, some argue that this imbalance is unlikely to be sustained over time [24].) This suggests that, in the longer term, the financial crisis leads to an increase in the relative attractiveness of producing investment goods in China. Moreover, this increase in investment is likely to have continued positive effects on China after 2020. In fact, by 2020, the yearly growth rates under the crisis are higher than those in the baseline (see Figure 4). As this continues into the future, eventually the cumulative growth rates in real GDP will exceed those in the baseline, and China will have gained from the financial crisis.

In terms of production, Table 6 indicates that China, with its large increases in investment, consequently experiences large increases in construction. For example, increases in investment in China due to the financial crisis drive a 25 percent increase in construction relative to the 2020 baseline. On the other hand, countries such as Japan and the US experience a reduction in investment, with the construction industry in these countries experiencing a substantial decline in output relative to the baseline.

Given the overall decline in global investment due to the crisis, we find the world construction industry is particularly hard-hit in terms of reduced output. We also find relatively significant reductions in global output of manufactured products. In general terms, sectors which are not so capital intensive tend to be relatively less adversely affected by the

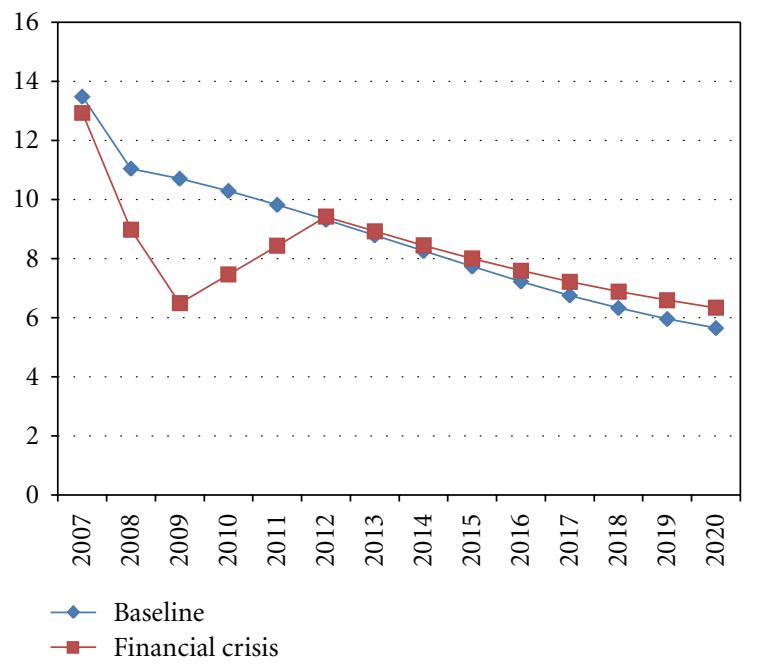

FIGURE 4: Year on year growth in real GDP in China under the baseline and with the crisis (\%).

financial crisis than those that are capital intensive. (See Strutt and Walmsley [25] for further discussion of these issues.) In China, sectoral output declines significantly less than the world average in all sectors except services (which is roughly equal to the world average). In fact, production of capital goods and construction in China increase due to the financial crisis.

Most countries also reduce exports and imports relative to the 2020 baseline, with Table 5 indicating the overall 
TABLE 6: Cumulative difference in real output due to financial crisis, China and selected countries, 2020 (\%).

\begin{tabular}{lccccc}
\hline & China & Japan & US & EU27 & World's total \\
\hline Crops & -4.2 & -6.3 & -5.3 & -8.5 & $-\mathbf{6 . 8}$ \\
Animals & -4.7 & -14.9 & -8.4 & -12.4 & $\mathbf{- 8 . 9}$ \\
Food processing & -8.1 & -12.0 & -9.4 & -11.9 & $-\mathbf{1 0 . 5}$ \\
Forestry and extraction & -3.3 & -12.2 & -6.5 & -7.9 & $-\mathbf{6 . 6}$ \\
Light manufactures & -13.6 & -19.9 & -15.5 & -15.9 & $-\mathbf{1 4 . 1}$ \\
Heavy manufactures & -4.8 & -19.8 & -16.1 & -17.4 & $-\mathbf{1 1 . 4}$ \\
Construction & 25.0 & -28.9 & -30.0 & -26.0 & $-\mathbf{1 6 . 0}$ \\
Services & -8.6 & -8.0 & -7.1 & -9.5 & $\mathbf{- 8 . 5}$ \\
\hline
\end{tabular}

Table 7: Cumulative difference in exports due to financial crisis, China and selected countries, 2020 (\%).

\begin{tabular}{lccccc}
\hline & China & Japan & US & EU27 & World's total \\
\hline Crops & -10.2 & -27.2 & -5.2 & -13.1 & $\mathbf{- 8 . 2}$ \\
Animals & -9.3 & -27.9 & -13.1 & -16.4 & $-\mathbf{1 3 . 4}$ \\
Food processing & -21.4 & -13.9 & -11.0 & -13.0 & $\mathbf{- 1 1 . 9}$ \\
Forestry and extraction & -32.6 & -3.4 & -2.6 & -1.3 & $\mathbf{- 9 . 8}$ \\
Light manufactures & -19.8 & -20.1 & -6.8 & -16.3 & $-\mathbf{1 5 . 8}$ \\
Heavy manufactures & -14.2 & -23.0 & -13.8 & -18.2 & $-\mathbf{1 3 . 6}$ \\
Construction & -22.1 & -12.6 & -5.3 & -17.8 & $-\mathbf{1 6 . 5}$ \\
Services & -36.2 & -15.1 & -2.8 & -14.3 & $-\mathbf{1 2 . 8}$ \\
\hline
\end{tabular}

changes in real exports and imports for China and other selected countries. The overall impact of the crisis on exports and imports is driven by investment and the realignment of trade balances resulting from the crisis. China experiences an increase in investment, declining trade balances, and relative appreciation of the real exchange rate, while the US and Europe experience declining investment, increasing trade balances, and a relative depreciation.

Turning to the declines in exports at a more detailed sectoral level in Table 7, we find that relatively strong export declines tend to be associated with the fairly strong output declines noted in Table 6, emphasizing the importance of trade to the sectoral output story. World exports of crops, along with forestry and extraction remain relatively robust; however, strong adverse impacts on exports from sectors such as construction and manufacturing are reflected in significantly reduced global output for these sectors. China's exports fall considerably more than production due to the relative appreciation of the real exchange rate caused by the increase in investment and the decline in the trade balance.

While global trade falls across all sectors, the declines are not uniform across sectors. China's imports fall considerably less than exports, and there are even some cases of increased trade to be found within this overall picture as shown in Table 8. The increases in demand for imports stem from a combination of (a) the rise in prices of domestic goods relative to imports in China, caused by the real appreciation of the RMB, (b) a decline in import prices of food and extraction due to the general decline in returns to land and natural resources, (c) the increase in demand for
TABLE 8: Cumulative difference in 2020 of imports due to financial crisis, China and selected countries (\%).

\begin{tabular}{lccccc}
\hline & China & Japan & US & EU27 & World's total \\
\hline Crops & -10.3 & -4.0 & -7.6 & -4.3 & $-\mathbf{7 . 2}$ \\
Animals & -15.9 & -1.3 & -2.3 & -10.3 & $-\mathbf{1 0 . 4}$ \\
Food processing & 0.7 & -10.4 & -7.7 & -11.8 & $-\mathbf{1 1 . 2}$ \\
Forestry and extraction & -4.3 & -13.7 & -12.5 & -13.9 & $-\mathbf{1 1 . 3}$ \\
Light manufactures & -9.5 & -20.1 & -23.7 & -19.2 & $-\mathbf{1 6 . 8}$ \\
Heavy manufactures & -11.4 & -11.8 & -13.9 & -14.7 & $-\mathbf{1 2 . 8}$ \\
Construction & -5.9 & -33.6 & -41.7 & -26.0 & $-\mathbf{1 2 . 0}$ \\
Services & 6.9 & -11.1 & -14.8 & -13.0 & $-\mathbf{1 2 . 3}$ \\
\hline
\end{tabular}

TABLE 9: Cumulative difference in selected macroeconomic variable under extended financial crisis relative to financial crisis, China and selected countries, 2020 (\% deviation).

\begin{tabular}{lcccc}
\hline & Real GDP, 2020 & Investment & Real exports & Real imports \\
\hline China & -1.6 & 3.9 & -3.7 & -1.9 \\
Japan & -1.4 & -2.3 & 7.1 & -3.9 \\
US & -1.8 & 0.0 & -1.7 & -1.8 \\
EU27 & -2.8 & -2.5 & -3.7 & -2.7 \\
\hline
\end{tabular}

construction and the assembly of investment goods in China, and/or (d) the fiscal stimulus packages.

4.1. Extended Financial Crisis. In the second scenario, we model an extended financial crisis with more protracted impacts than the first scenario.

Comparing the results of selected indicators for the ex-tended financial crisis with the financial crisis scenario (Table 9), not surprisingly, we find that the impacts are now more severe. While 2010, real GDP variations from the baseline will be identical to the moderate crisis scenario, by 2020 real GDP has declined further for all economies as indicated in the first column of Table 9. This is primarily due to the improvement in investment being delayed, which in turn delays capital accumulation. The further decline in global GDP and incomes also causes global savings and investment to fall $(-3.2$ percent relative to the financial crisis scenario). The impact on investment differs across countries, implying that there is a further re-reallocation of investment, resulting from the more gradual adjustment in expectations. Figure 5 indicates that if the financial crisis is protracted, investment tends to be reallocated towards China during the period of extended crisis to 2015. However, the cumulative increase in investment in China by 2020 is lower under the assumptions of the extended crisis.

An examination of the aggregate trade results indicates that exports across every sector decline significantly more under the extended crisis scenario, with the total world export volume declining by 3 percent more than the financial crisis. These changes in aggregate exports are also reflected in output changes by sector and region. Table 10 indicates that while a similar relative sector pattern exists between the first and second scenarios, almost all sectors experience a more 


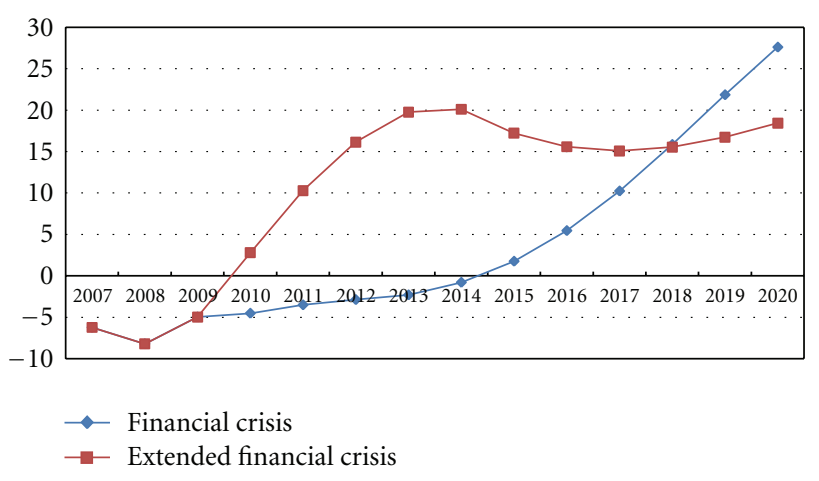

FIGURE 5: Cumulative difference in investment from the baseline, China with financial crisis and extended financial crisis (\%).

TABLE 10: Cumulative difference in output, extended financial crisis relative to financial crisis, China and selected countries, 2020 (\%).

\begin{tabular}{lccccc}
\hline & China & Japan & US & EU27 & World's total \\
\hline Crops & -0.6 & -0.4 & -1.1 & -1.7 & $-\mathbf{1 . 6}$ \\
Animals & -1.0 & -1.2 & -1.7 & -2.6 & $-\mathbf{2 . 2}$ \\
Food processing & -1.6 & -1.7 & -1.9 & -2.5 & $-\mathbf{2 . 5}$ \\
Forestry and extraction & -0.5 & -0.8 & -1.1 & -1.6 & $-\mathbf{2 . 1}$ \\
Light manufactures & -2.5 & 4.4 & -0.9 & -3.0 & $-\mathbf{2 . 4}$ \\
Heavy manufactures & -1.6 & 2.4 & -1.5 & -3.4 & $-\mathbf{2 . 3}$ \\
Construction & 3.6 & -2.0 & -0.7 & -2.6 & $-\mathbf{2 . 0}$ \\
Services & -2.2 & -1.8 & -1.9 & -2.9 & $\mathbf{- 2 . 8}$ \\
\hline
\end{tabular}

significant decline in output under the more severe crisis scenario. The exception here is the Chinese construction sector, along with a slight increase in manufactured exports for Japan.

\section{Concluding Comments}

The global financial crisis continues to have a significant impact on many economies. While the direct impact on the Chinese economy might be considered rather limited, there may be long-run implications, driven in part by changes in investment. In this paper, we used historical data and forecasts in an effort to model the impacts of the crisis within a general equilibrium framework. While the GDyn model used offers a way of modeling how the expected changes in real GDP and investment are likely to work their way through each economy and sector over time, the current study of course has limitations. Of particular note, is that the dynamic CGE model used does not include debt or money obligations; therefore, it does not offer insights into the causes or the total macroeconomic impact of the crisis. We are reliant on other sources for these insights and we note that there have been ongoing modifications to the projections released by international agencies since our modeling was undertaken, with significant uncertainty still remaining in the global economy. A further limitation is that the model used here only incorporates the accumulation of capital; it does not take into account the accumulation of stocks and in particular the accumulation of natural resources for future use.

Our findings here suggest that the crisis is likely to have a significant effect on trade, due in part to the changes in capital flows resulting from the reallocation of savings across regions. In the short run, all countries including China suffer from the crisis. In the long run, countries such as the US and the EU experience a persistent decline in real GDP, while countries such as China recoup some of the losses. Globally, our results suggest that trade falls by 13.7 percent from the 2020 baseline, and the composition of trade changes quite markedly as a result of the crisis, with shifts reflecting changes in demand for construction of investment goods and the increasing demands of economies such as China. The reallocation of investment towards China is likely to result in eventual gains to China from the crisis, as the higher accumulation of capital leads to higher real GDP, although these are not seen until well after 2020.

A longer-lasting crisis, as modeled in our second scenario, further harms most economies, including China, though with some investment reallocation towards China during the years of the extended crisis in the US and the EU.

\section{Acknowledgment}

This paper draws on a broader study undertaken for UNESCAP [25]. The authors gratefully acknowledge the support of UNESCAP, particularly assistance and advice from Mia Mikic. Support was also generously provided by the Waikato Management School. they thank Kym Anderson and Alan Deardorff for very useful discussion on an earlier version of this study. Thanks are also due to the anonymous reviewers.

\section{References}

[1] World Bank, "Global economic prospects 2011: navigating strong currents," Report, World Bank, Washington, DC, USA, 2011.

[2] E. Ianchovichina and R. McDougall, Theoretical Structure of Dynamic GTAP. GTAP Technical Paper No. 17, 2000.

[3] T. W. Hertel, Ed., Global Trade Analysis: Modeling and Applications, Cambridge University Press, New York, NY, USA, 1997.

[4] B. G. Narayanan and T. L. Walmsley, Eds., Global Trade, Assistance, and Production: The GTAP 7 Data Base, Centre for Global Trade Analysis, Purdue University, 2008.

[5] R. McDougall, T. L. Walmsley, A. Golub, E. Ianchovichina, and K. Itakura, "An Overview of the Dynamic GTAP Data Base: The Data Base Construction and Aggregation Programs," in Dynamic Modeling and Applications in Global Economic Analysis, E. Ianchovichina and T. L. Walmsley, Eds., Cambridge University Press.

[6] P. Adams and B. Parmenter, Economic Forecasting, Allen and Unwin Academic, Sydney, Australia, 2000.

[7] T. L. Walmsley, A Baseline Scenario for the Dynamic GTAP Model, Centre for Global Trade Analysis, Purdue University, West Lafayette, Ind, USA, 2006. 
[8] P. Dixon and M. Rimmer, Dynamic General Equilibrium Modelling for Forecasting and Policy, Elsevier, Amsterdam, The Netherlands, 2002.

[9] T. L. Walmsley and A. Strutt, "A Baseline for the GDyn Model," in Proceedings of the 12th Annual Conference on Global Economic Analysis Santiago, Chile, June 2009.

[10] World Bank, World Development Indicators, World Bank, Washington, DC, USA, 2009.

[11] L. R. Ngai and C. A. Pissarides, "Structural change in a multisector model of growth," American Economic Review, vol. 97, no. 1, pp. 429-443, 2007.

[12] T. W. Hertel, C. E. Ludena, and A. Golub, "Economic growth, technological change, and patterns of food and agricultural trade in Asia," ERD Working Paper Series, no. 86, pp. 1-57, 2006.

[13] A. Golub, T. W. Hertel, and B. Sohngen, "Projecting land use change in the dynamic GTAP framework," in Proceedings of the 10th Annual Conference on Global Economic Analysis, Purdue University, West Lafayette, Ind, USA, 2007.

[14] OECD, STAN Indicators Database. Paris: OECD Directorate for Science, Technology and Industry, 2005.

[15] W. Kets and A. M. Lejour, Sectoral TFP Growth in the OECD. CPB Memorandum, 58, Netherlands Bureau of Economic Analysis, The Hague, The Netherlands, 2003.

[16] A. Golub, T. W. Hertel, and B. Sohngen, "Land Use Modeling in Recursively-Dynamic GTAP Framework," 2008.

[17] World Bank, "Global development finance: charting a global recovery," Report, World Bank, Washington, DC, USA, 2009.

[18] A. Strutt and T. L. Walmsley, "Trade and Sectoral Impacts of the Financial Crisis: A Dynamic CGE Analysis," in Proceedings of the ARTNet Asia-Pacific Trade Economists': Trade-Led Growth in Times of Crisis, Bangkok, Thailand, November 2009.

[19] A. Elbehri and K. R. Pearson, Implementing Bilateral Tariff Rate Quotas in GTAP using GEMPACK. GTAP Tech Paper 18, 2005.

[20] C. Freedman, M. Kumhof, D. Laxton, and J. Lee, The Case for Global Fiscal Stimulus. IMF Staff Position Note SPN/09/03, 2009.

[21] M. Horton and A. Ianova, The Size of the Fiscal Expansion: An Analysis for the Largest Countries. Washington, DC, USA, International Monetary Fund, 2009.

[22] IMF, Global Economic Prospects and Policy Challenges. Washington, DC, USA, International Monetary Fund, 2009.

[23] B. J. Eichengreen and D. A. Irwin, The Slide to Protectionism in the Great Depression: Who Succumbed and Why? NBER Working Paper No. w15142, 2009.

[24] M. S. Feldstein, The Role of Currency Realignments in Eliminating the US and China Current Account Imbalances. NBER Working Paper No. 16674, 2011.

[25] A. Strutt and T. L. Walmsley, Trade and Sectoral Impacts of the Global Financial Crisis: A Dynamic CGE Analysis In United Nations ESCAP (Ed.). Bangkok, Thailand, UNESCAP, 2011. 


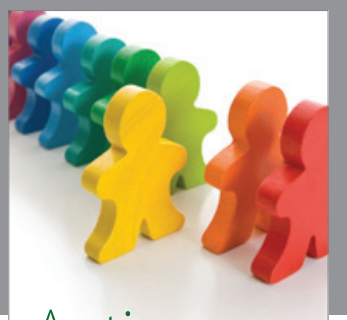

Autism

Research and Treatment
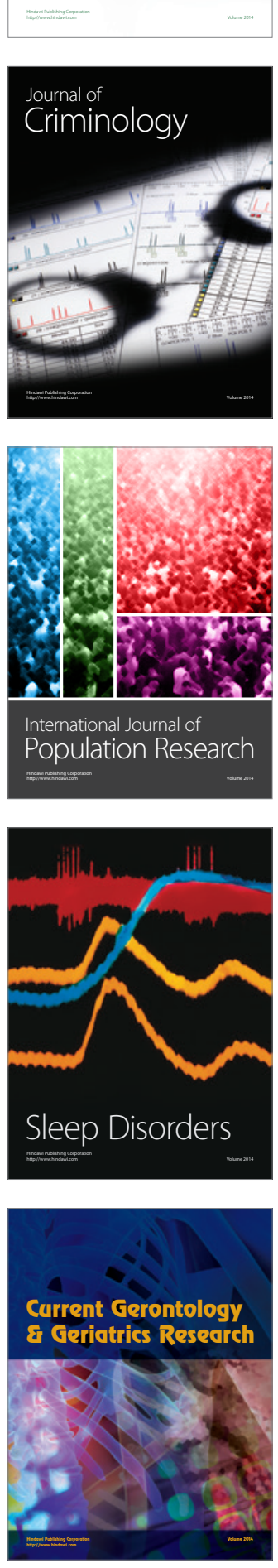
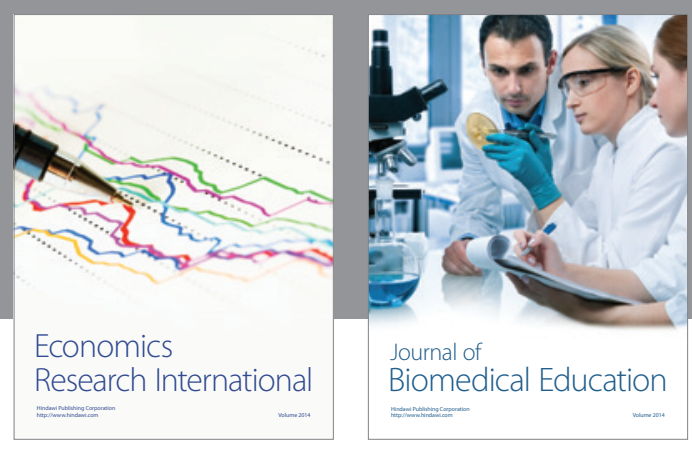

Journal of

Biomedical Education

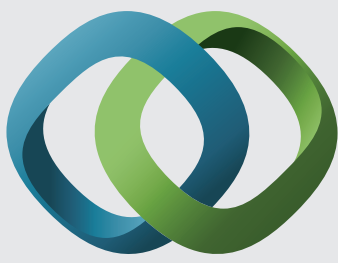

\section{Hindawi}

Submit your manuscripts at

http://www.hindawi.com
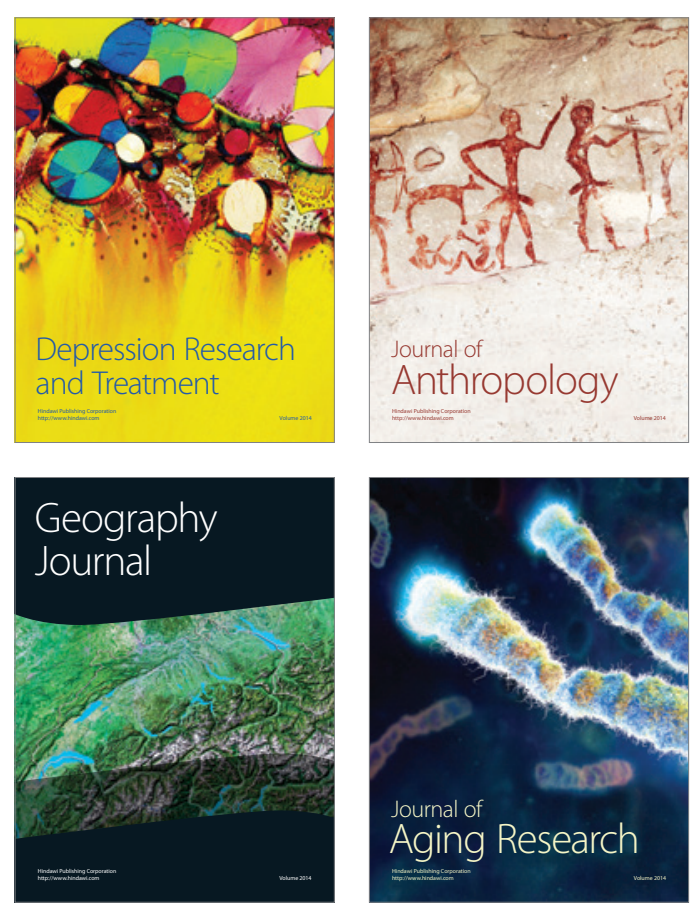

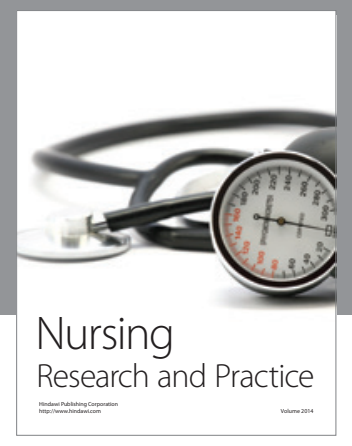

Nursing

Research and Practice

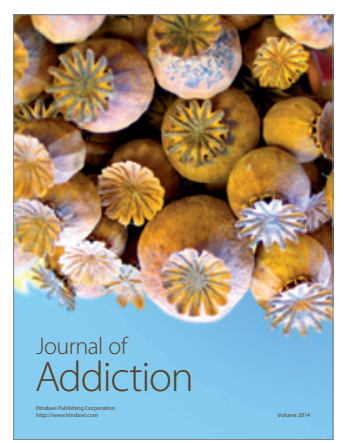

Child Development

Research

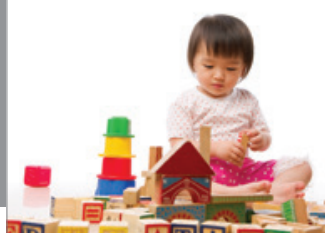

迥
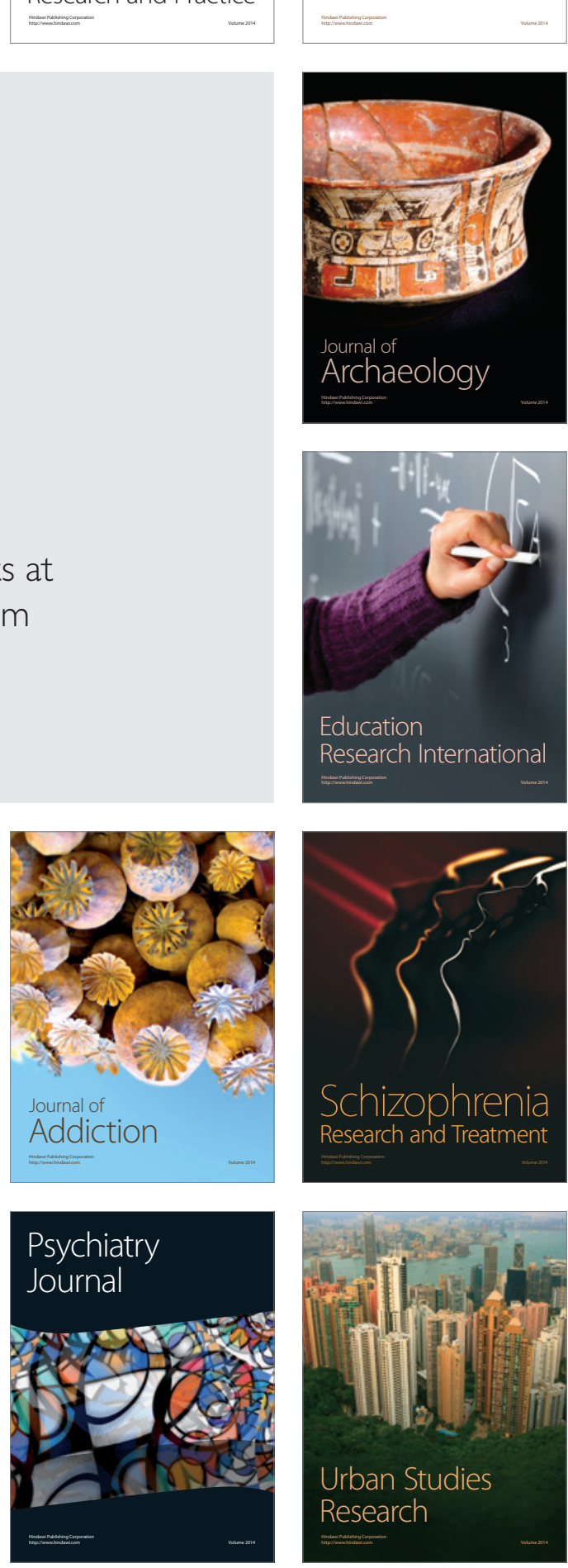